\title{
Managing a patient with burning mouth syndrome
}

\author{
Danny Cheung, Nigel Trudgill
}

Department of Gastroenterology, Sandwell General Hospital, West Bromwich, UK

\section{Correspondence to} Dr NJ Trudgill, Sandwell General Hospital, Lyndon, West Bromwich B71 4HJ, UK; nigel.trudgill@nhs.net

Received 2 March 2014 Revised 23 May 2014 Accepted 26 May 2014 Published Online First 17 June 2014

\section{CrossMark}

$$
\begin{aligned}
& \hline \text { To cite: Cheung D, } \\
& \text { Trudgill N. Frontline } \\
& \text { Gastroenterology } \\
& \text { 2015;6:218-222. }
\end{aligned}
$$

\section{ABSTRACT}

A 64-year-old woman presented with an increasing frequency of symptoms of heartburn and retrosternal pain over the last few months, and a constant and intense burning pain affecting her tongue tip, mouth and lips for the past 5 years. She found consuming hot drinks exacerbated the burning oral pain and chewing gum seemed to alleviate some of her symptoms. She thought these oral sensations were caused by frequently licking her finger tips to separate prints in her work in publishing. She had been previously diagnosed with gastro-oesophageal reflux disease (GORD), and her heartburn symptoms had been controlled until recently with lansoprazole $15 \mathrm{mg}$ daily. Her past medical history included irritable bowel syndrome and depression, for which she had been treated with mebeverine and paroxetine for a number of years. She was a non-smoker and did not consume alcohol. Clinical examination was unremarkable with no oral lesions on examination. Her routine laboratory tests, including autoimmune serology, haematinics and thyroid function tests were all within normal limits. She underwent a gastroscopy, which revealed moderate reflux oesophagitis, and following commencing omeprazole $20 \mathrm{mg}$ twice daily, her heartburn resolved. However, her oral burning symptoms were not affected and a diagnosis of burning mouth syndrome (BMS) was made. Following explanation and reassurance concerning the cause of her BMS symptoms, she chose not to receive treatment for this but to access cognitive behavioural therapy in the future if her symptoms worsened.

\section{INTRODUCTION}

Burning mouth syndrome (BMS), also known as burning tongue syndrome, glossodynia, glossopyrosis and stomatopyrosis, is a chronic idiopathic condition, in which a burning pain is experienced in the tongue or other oral mucous membranes. It can be associated with related symptoms, such as subjective xerostomia (dryness of the mouth) and dysgeusia (altered taste perception or a persistent bitter or metallic taste). ${ }^{1}$ Idiopathic BMS is a diagnosis of exclusion and defined by the International Headache Society as an 'intraoral burning sensation for which no medical or dental cause can be found'. ${ }^{2}$ This should be differentiated from secondary BMS in which similar symptoms can be caused by a number of medical or dental conditions, which are discussed in more detail later in the article.

Idiopathic BMS predominately affects postmenopausal women with studies reporting that over $80 \%$ of BMS patients are women and an average age at diagnosis in the late fifties. ${ }^{1}{ }^{3}$ The peak age of onset is from 3 years before to 12 years after the menopause, with BMS patients experiencing significantly more severe menopausal symptoms when compared with age-matched controls. ${ }^{1} 3$ There is a wide variability in the prevalence of BMS in published studies, largely due to differences in age and gender between the populations studied, and that some studies included patients with oral burning from other causes. The overall reported prevalence for idiopathic BMS is between 0.7\% and $7.9 \%$, with a prevalence of up to $12 \%$ in postmenopausal women. ${ }^{3-5}$

The aetiology of idiopathic BMS is not fully understood, but it is thought to be multifactorial with local, systemic and psychological factors all thought to be important. $^{3}$ A neurophysiological dysfunction model has been suggested by tongue biopsies from idiopathic BMS patients revealing a loss of small-diameter nerve fibres in the tongue epithelium, and also diffuse morphological changes in subpapillary nerve bundles reflecting axonal degeneration. ${ }^{6} 7$ Idiopathic BMS patients are also less tolerant of localised induced pain at the tongue tip, where the majority of BMS patients experience 
symptoms, with the sensation lasting longer when compared with controls following stimulus withdrawal, suggesting a component of impaired central pain processing. ${ }^{8}$

\section{CLINICAL FEATURES}

There is currently no one universally accepted classification system for idiopathic BMS. ${ }^{9}$ It can be classified clinically into three subtypes based on the pattern of symptoms. ${ }^{10}{ }^{11}$ Type 1 affects approximately $35 \%$ of BMS patients. Typically, patients are asymptomatic when they wake up, but continuous pain usually starts by mid-morning or early afternoon, with the maximum pain intensity usually reached by early evening. In type 2 , affecting $55 \%$ of BMS patients, symptoms are constant throughout the day, and patients find it difficult to get to sleep. Type 2 BMS patients usually present with associated psychological disorders. Patients with type 3 BMS (10\% of all BMS patients) have intermittent symptoms with an atypical location and/or pain. The majority of BMS patients report idiopathic symptoms affecting other areas of the body, with over $80 \%$ of these being pain related. ${ }^{12} 13$ Recently, attempts have been made to subclassify idiopathic BMS into those with a predominantly central, a peripheral or a mixed pattern, depending on response to lingual nerve block ${ }^{14}$ or site of neuropathological, neurophysiological or functional imaging abnormalities. ${ }^{9}$

Most idiopathic BMS patients experience bilateral burning of the oral mucosa, with the tongue the most commonly affected area (table 1). ${ }^{1}$ The symptoms may be accompanied by nausea, headaches and dizziness in around one-fifth of patients. ${ }^{13}$ Exacerbating factors may include stress, fatigue, speaking and consumption of hot food. Resting and exercising do not modify the pain in the majority of patients. Patients often find sleeping, eating cold food, working, distraction and alcohol help ease symptoms.

\section{DIAGNOSIS AND INVESTIGATION}

There is frequently a substantial delay between the onset of symptoms and a definitive diagnosis, often due to a lack of awareness of BMS among medical and dental practitioners. Patients consult, on average,

Table 1 Common oral sites affected by burning mouth syndrome $^{1}$

\begin{tabular}{ll}
\hline Anatomical sites & $\begin{array}{l}\text { Proportion of } \\
\text { patients affected (\%) }\end{array}$ \\
\hline Tongue (tip) & 78 \\
Tongue (anterior two-thirds) & 58 \\
Hard palate (anterior one-third) & 49 \\
Lower lip & 49 \\
Upper lip & 39 \\
Hard palate (posterior two-thirds) & 26 \\
\hline
\end{tabular}

three medical or dental practitioners over a period of 34 months before BMS is diagnosed. ${ }^{15}$ Idiopathic BMS is a diagnosis of exclusion with the current diagnostic criteria requiring daily symptoms of oral pain, which persist for most of the day, with a normal oral mucosal appearance.

There are several medical and dental conditions, which have been described as a cause of oral burning or pain, which need to be considered before diagnosing idiopathic BMS (table 2). ${ }^{10}{ }^{15-18}$ BMS is not caused by gastro-oesophageal reflux disease (GORD), but BMS patients can be referred to gastroenterology clinics with a suspected diagnosis of GORD, due to the burning quality of the pain. However, GORD can be differentiated from BMS due to the intermittent nature of the symptoms in GORD. A detailed history, including past medical history, current medications, previous dental procedures and use of dental prosthetics should be elicited. Additionally, particular attention should be paid to symptoms of anxiety and depression, given their association with idiopathic BMS. However, the severity of anxiety or depression does not appear to directly correlate with the intensity of BMS symptoms. ${ }^{3}$ It is also important to explore the patient's beliefs and additional factors that may contribute to BMS, including recent bereavement, housing issues, domestic problems and fear of cancer, as addressing these issues may contribute to the treatment of BMS. ${ }^{10}$ A thorough oral clinical examination including dental inspection, with special emphasis on detecting oral soft tissue lesions associated with anaemia, geographic tongue, nutritional deficiency and signs of poorly fitting dentures should be undertaken.

A series of screening blood tests should be considered in all patients presenting with BMS, including full blood count, serum glucose, haematinics (vitamin $\mathrm{B}_{12}$, folate, ferritin), calcium, magnesium, zinc and autoimmune serology to exclude treatable causes. Oral biopsy and salivary flow rate are rarely required, unless the history or clinical examination suggest features of mucocutaneous disease (such as lichen

Table 2 Differential diagnosis of burning mouth syndrome ${ }^{10} 15-18$

\begin{tabular}{ll}
\hline Systemic & Local \\
\hline Diabetes & Oral lichen planus \\
Hypothyroidism & Migratory glossitis \\
Anaemia & (geographic tongue) \\
Cerebrovascular disease & Dental and periodontal diseases \\
Multiple sclerosis & Temporomandibular disorders \\
Autoimmune disorders & Diseases of the salivary glands \\
(eg, Sjögren's syndrome) & Sinusitis \\
Medication (eg, angiotensin- & Postherpetic neuralgia \\
converting enzyme inhibitors) & Trigeminal neuralgia \\
Nutritional deficiency & Allergy to food or dental materials \\
(vitamin B, iron and zinc) & Poorly fitted oral prosthesis/dentures \\
Non-metastatic lung cancer & Overusing mouthwashes \\
Metastatic malignancies & Overbrushing tongue \\
Gastro-oesophageal reflux disease & \\
\hline
\end{tabular}


planus, benign mucous membrane pemphigoid or migratory glossitis) or Sjögren's syndrome.

\section{MANAGEMENT}

Idiopathic BMS can significantly impact on quality of life $;{ }^{19} 70 \%$ of BMS patients report mood changes and over half have changed their eating habits following the onset of BMS. More significantly, 20\% of BMS patients experience depression and a reduced desire to socialise. $^{1}$

Idiopathic BMS can be challenging to manage, with less than $30 \%$ of patients experiencing a reduction or resolution of symptoms following treatment, although around $10 \%$ of patients do spontaneously improve without any treatment within 5 years of the initial onset of symptoms. ${ }^{20} \mathrm{~A}$ key aim of BMS management is to provide psychological support by recognising and acknowledging the patient's symptoms, in addition to exploring and addressing issues which may contribute to their symptoms. This is combined with pharmacological and non-pharmacological management for symptom control. The recent Cochrane review found there was a lack of high-grade evidence to guide the management of BMS, as the majority of the published studies to date are uncontrolled and involve only a small number of subjects, with some including subjects with burning mouth symptoms from other causes, rather than idiopathic BMS, making treatment comparisons difficult. ${ }^{21}$

\section{Cognitive behavioural therapy}

A small randomised controlled trial investigated the role of cognitive behavioural therapy (CBT) weekly for 12 weeks in 30 BMS patients compared with placebo (3 follow-up sessions over 12 weeks). The study reported that the CBT group had significantly reduced pain intensity at 6 months after treatment when compared with the placebo group. In the CBT group, $27 \%$ of the patients were symptom-free at 6 months compared with $0 \%$ in the placebo group. ${ }^{22}$ Two further uncontrolled studies with a total of 68 patients with BMS also reported a reduction in pain and anxiety levels following CBT. ${ }^{23}{ }^{24}$ Despite a lack of high-quality evidence, there is some evidence to suggest CBT is worth considering in the treatment of BMS.

\section{Antidepressants}

In a single-blind head-to-head study, 76 BMS patients were randomised to amisulpride $50 \mathrm{mg}$, paroxetine $20 \mathrm{mg}$ or sertraline $50 \mathrm{mg}$ daily for 8 weeks. $^{25}$ All three drugs improved pain intensity, anxiety and depression scores significantly from baseline assessment by the end of the treatment period. However, the low number of patients included and the lack of a control group in this study, hamper interpretation of these results. Furthermore, $45 \%$ of the patients had a concurrent psychiatric diagnosis in this trial. Despite the widespread use of tricyclic antidepressants in BMS, in the only placebo-controlled study, trazodone $200 \mathrm{mg}$ daily was shown to be no more effective in reducing pain-related symptoms than placebo, and was associated with one-third of patients withdrawing from the trial due to side effects. ${ }^{26}$ The evidence for the use of antidepressants for the treatment of BMS is inconclusive, but they may have a role in treating coexistent anxiety or depression.

\section{Topical benzodiazepines}

In a placebo-controlled study of 48 BMS patients, clonazepam $1 \mathrm{mg}$ lozenges were sucked three times a day and reduced pain significantly compared with a placebo lozenge after 2 weeks of treatment. ${ }^{27} \mathrm{~A}$ recent placebo-controlled study in 20 BMS patients reported a significant reduction in pain following $0.5 \mathrm{mg}$ of oral clonazepam daily for 9 weeks in this study. ${ }^{28}$ However, concerns about systemic absorption of topical or systemic therapy, potential dependence especially for systemic clonazepam, and a lack of long-term data limit its potential value in the therapy of BMS.

\section{Alpha-lipoic acid}

There is some evidence to suggest that BMS patients have an increase in oxidative stress. ${ }^{29} \alpha$-Lipoic acid (ALA) is a free-radical scavenger which has been studied in BMS patients. Initial trials suggested that ALA for up to 2 months can improve symptoms in up to $70 \%$ of BMS subjects. ${ }^{30-32}$ However, subsequent, larger, randomised, placebo-controlled trials have not demonstrated the same benefit due to a high rate of placebo response. ${ }^{33}{ }^{34}$ Due to the conflicting evidence, ALA is not currently indicated in BMS patients.

\section{Hormone replacement therapy}

Given the strong link between the menopause and BMS, hormone replacement therapy (HRT) would appear an attractive therapy. However, there are currently no adequate placebo-controlled trials of HRT in BMS, and only three open studies that are of limited value. ${ }^{35-37}$ There is, therefore, no evidence to recommend HRT as a treatment for BMS at present, despite the association of BMS with the menopause.

\section{Capsaicin}

Capsaicin is the active component of chilli peppers, and has a role in the therapy of neuropathic pain through inhibition of the biosynthesis and axonal transport of substance P. Topical capsaicin $0.025 \%$ gel and capsaicin $0.02 \%$ mouth rinse have both been reported to be of symptomatic benefit in BMS patients in case series, although both can be poorly tolerated in a proportion of patients due to their bitter taste, and they may also cause a burning sensation. ${ }^{38}{ }^{39}$ A further case series reported that systemic oral capsaicin $0.25 \%$ improved symptoms in the short term in patients with BMS during 30 days of 
treatment. ${ }^{40}$ This was most marked in patients with severe symptoms at baseline, and over $90 \%$ reported a reduction in symptoms following treatment. However, around a third of the patients experienced significant gastric pain during treatment. Due to the lack of highquality evidence from a randomised controlled trial and potential side effects, topical and systemic capsaicin cannot currently be recommended in the treatment of BMS.

\section{Acupuncture}

Acupuncture is a branch of traditional Chinese medicine that has been used in chronic pain management in Western medicine. Two small pilot studies reported that acupuncture for 8 weeks improved pain slightly although did not significantly improve quality of life, ${ }^{41}$ but when carried out monthly for 6 months can lead to symptom reduction for up to 18 months following treatment. ${ }^{42}$ However, due to the small number of patients studied and lack of controlled data, no conclusion can be reached on its value in BMS.

\section{Tongue protector}

BMS patients may have parafunctional habits such as tongue thrusting or tics causing continuous rubbing of oral structures, which can contribute to and maintain BMS. The application of a tongue protector (a thin transparent polyethylene sheath) covering the tongue with habit-modifying therapy has been shown to improve pain intensity under these circumstances. ${ }^{43}$ The use of such devices may be beneficial in selected cases.

\section{CONCLUSIONS}

Idiopathic BMS is a relatively common condition that mainly affects postmenopausal women. It is often poorly recognised by medical and dental practitioners, leading to a delay in diagnosis and treatment. It is important to consider other oral and systemic causes of oral burning before diagnosing idiopathic BMS. The treatment strategy should be tailored to patient preference and local service availability, in the absence of high-grade evidence to guide management. Coexisting anxiety and depression should be treated.

\section{WEB RESOURCES}

International Headache Society http://www.ihs-headache.org The Cochrane Library http://www.bibliotecacochrane.com/ pdf/CD002779.pdf

British Dental Health Foundation http://www.dentalhealth. org

Contributors DC and NT conducted literature review, drafted and revised the paper.

Competing interests None.

Patient consent Obtained.

Provenance and peer review Not commissioned; externally peer reviewed.

\section{REFERENCES}

1 Grushka M. Clinical features of burning mouth syndrome. Oral Surg Oral Med Oral Pathol 1987;63:30-6.

2 Headache Classification Subcommittee of the International Headache S. The International Classification of Headache Disorders: 2nd edition. Cephalalgia 2004;24(Suppl 1):9-160.

3 Bergdahl M, Bergdahl J. Burning mouth syndrome: prevalence and associated factors. J Oral Pathol Med 1999;28:350-4.

4 Tammiala-Salonen T, Hiidenkari T, Parvinen T. Burning mouth in a Finnish adult population. Community Dent Oral Epidemiol 1993;21:67-71.

5 Lipton JA, Ship JA, Larach-Robinson D. Estimated prevalence and distribution of reported orofacial pain in the United States. J Am Dent Assoc 1993;124:115-21.

6 Lauria G, Majorana A, Borgna M, et al. Trigeminal small-fiber sensory neuropathy causes burning mouth syndrome. Pain 2005;115:332-7.

7 Penza P, Majorana A, Lombardi R, et al. "Burning tongue" and "burning tip": the diagnostic challenge of the burning mouth syndrome. Clin J Pain 2010;26:528-32.

8 Grushka M, Sessle BJ, Howley TP. Psychophysical assessment of tactile, pain and thermal sensory functions in burning mouth syndrome. Pain 1987;28:169-84.

9 Jaaskelainen SK. Pathophysiology of primary burning mouth syndrome. Clin Neurophysiol 2012;123:71-7.

10 Lamey PJ, Lamb AB. Prospective study of aetiological factors in burning mouth syndrome. $\mathrm{Br}$ Med J (Clin Res Ed) 1988;296:1243-6.

11 Lopez-Jornet P, Camacho-Alonso F, Andujar-Mateos P, et al. Burning mouth syndrome: an update. Med Oral Patol Oral Cir Bucal 2010;15:e562-8.

12 Mignogna MD, Pollio A, Fortuna G, et al. Unexplained somatic comorbidities in patients with burning mouth syndrome: a controlled clinical study. J Orofac Pain 2011;25:131-40.

13 Gaitonde P, Rostron J, Longman L, et al. Burning mouth syndrome and vulvodynia coexisting in the same patient: a case report. Dent Update 2002;29:75-6.

14 Gremeau-Richard C, Dubray C, Aublet-Cuvelier B, et al. Effect of lingual nerve block on burning mouth syndrome (stomatodynia): a randomized crossover trial. Pain 2010;149:27-32.

15 Mignogna MD, Fedele S, Lo Russo L, et al. The diagnosis of burning mouth syndrome represents a challenge for clinicians. J Orofac Pain 2005;19:168-73.

16 Basker RM, Sturdee DW, Davenport JC. Patients with burning mouths. A clinical investigation of causative factors, including the climacteric and diabetes. Br Dent J 1978;145:9-16.

17 Main DM, Basker RM. Patients complaining of a burning mouth. Further experience in clinical assessment and management. Br Dent J 1983;154:206-11.

18 Zegarelli DJ. Burning mouth: an analysis of 57 patients. Oral Surg Oral Med Oral Pathol 1984;58:34-8.

19 Lopez-Jornet P, Camacho-Alonso F, Lucero-Berdugo M. Quality of life in patients with burning mouth syndrome. J Oral Pathol Med 2008;37:389-94.

20 Sardella A, Lodi G, Demarosi F, et al. Burning mouth syndrome: a retrospective study investigating spontaneous remission and response to treatments. Oral Dis 2006;12:152-5.

21 Zakrzewska JM, Forssell H, Glenny AM. Interventions for the treatment of burning mouth syndrome. Cochrane Database Syst Rev 2005;(1):CD002779. 
22 Bergdahl J, Anneroth G, Perris H. Cognitive therapy in the treatment of patients with resistant burning mouth syndrome: a controlled study. J Oral Pathol Med 1995;24:213-15.

23 Komiyama O, Nishimura H, Makiyama Y, et al. Group cognitive-behavioral intervention for patients with burning mouth syndrome. J Oral Sci 2013;55:17-22.

24 Miziara ID, Filho BC, Oliveira R, et al. Group psychotherapy: an additional approach to burning mouth syndrome. J Psychosom Res 2009;67:443-8.

25 Maina G, Vitalucci A, Gandolfo S, et al. Comparative efficacy of SSRIs and amisulpride in burning mouth syndrome: a single-blind study. J Clin Psychiatry 2002;63:38-43.

26 Tammiala-Salonen T, Forssell H. Trazodone in burning mouth pain: a placebo-controlled, double-blind study. J Orofac Pain 1999;13:83-8.

27 Gremeau-Richard C, Woda A, Navez ML, et al. Topical clonazepam in stomatodynia: a randomised placebo-controlled study. Pain 2004;108:51-7.

28 Heckmann SM, Kirchner E, Grushka M, et al. A double-blind study on clonazepam in patients with burning mouth syndrome. Laryngoscope 2012;122:813-16.

29 Woda A, Dao T, Gremeau-Richard C. Steroid dysregulation and stomatodynia (burning mouth syndrome). J Orofac Pain 2009;23:202-10.

30 Femiano F, Gombos F, Scully C, et al. Burning mouth syndrome (BMS): controlled open trial of the efficacy of alpha-lipoic acid (thioctic acid) on symptomatology. Oral Dis 2000;6:274-7.

31 Femiano F. Burning mouth syndrome (BMS): an open trial of comparative efficacy of alpha-lipoic acid (thioctic acid) with other therapies. Minerva Stomatol 2002;51:405-9.

32 Femiano F, Scully C. Burning mouth syndrome (BMS): double blind controlled study of alpha-lipoic acid (thioctic acid) therapy. J Oral Pathol Med 2002;31:267-9.

33 Carbone M, Pentenero M, Carrozzo M, et al. Lack of efficacy of alpha-lipoic acid in burning mouth syndrome: a double-blind, randomized, placebo-controlled study. Eur J Pain 2009;13:492-6.

34 Cavalcanti DR, da Silveira FR. Alpha lipoic acid in burning mouth syndrome-a randomized double-blind placebo-controlled trial. J Oral Pathol Med 2009;38:254-61.

35 Ferguson MM, Carter J, Boyle P, et al. Oral complaints related to climacteric symptoms in oophorectomized women. J R Soc Med 1981;74:492-8.

36 Forabosco A, Criscuolo M, Coukos G, et al. Efficacy of hormone replacement therapy in postmenopausal women with oral discomfort. Oral Surg Oral Med Oral Pathol 1992;73:570-4.

37 Pisanty S, Rafaely B, Polishuk W. The effect of steroid hormones on buccal mucosa of menopausal women. Oral Surg Oral Med Oral Pathol 1975;40:346-53.

38 Epstein JB, Marcoe JH. Topical application of capsaicin for treatment of oral neuropathic pain and trigeminal neuralgia. Oral Surg Oral Med Oral Pathol 1994;77:135-40.

39 Silvestre FJ, Silvestre-Rangil J, Tamarit-Santafe C, et al. Application of a capsaicin rinse in the treatment of burning mouth syndrome. Med Oral Patol Oral Cir Bucal 2012;17: e1-4.

40 Petruzzi M, Lauritano D, De Benedittis M, et al. Systemic capsaicin for burning mouth syndrome: short-term results of a pilot study. J Oral Pathol Med 2004;33:111-14.

41 Sardella A, Lodi G, Tarozzi M, et al. Acupuncture and burning mouth syndrome: a pilot study. Pain Pract 2013;13:627-32.

42 Scardina GA, Ruggieri A, Provenzano F, et al. Burning mouth syndrome: is acupuncture a therapeutic possibility? $\mathrm{Br}$ Dent $\mathrm{J}$ 2010;209:E2.

43 Lopez-Jornet P, Camacho-Alonso F, Molino-Pagan D. Prospective, randomized, double-blind, clinical evaluation of Aloe vera Barbadensis, applied in combination with a tongue protector to treat burning mouth syndrome. J Oral Pathol Med 2012;42:295-301. 